\title{
Biologia das células-tronco mesenquimais de felinos obtidas a partir de nichos presentes no tecido adiposo para aplicação terapêutica na medicina veterinária
}

Enrico Santos
CELLTROVET - Células-tronco Aplicadas a Medicina

Veterinária Personalizada, Laboratório de Biotecnologia e Inovação Tecnológica, São Paulo, SP, Brasil.

E-mail: enricosantos@celltrovet.com.br

Recebido em: 30 outubro 2017. Aceito em: 7 fevereiro 2018.

DOI: http://dx.doi.org/10.21674/2448-0479.43.368-379

\section{Resumo}

O tecido adiposo vem representando uma fonte em potencial para a obtenção de células-tronco mesenquimais (CTMs). Estudos recentes têm demonstrado que as CTMs apresentam potencial de utilização tanto na pesquisa básica como aplicada. Podendo ser obtidas, em grandes quantidades, por meio de anestesia local e com o mínimo de desconforto, as CTMs vêm sendo objeto de intensa pesquisa. Neste estudo, o tecido adiposo de felino, obtido por meio de biópsia realizada na região subcutânea, foi processado de forma a obter uma população celular morfologicamente homogênea. As células-tronco mesenquimais derivadas do tecido adiposo de felinos (CTMs-TAF) foram mantidas, in vitro, em crescimento exponencial até a 9a passagem apresentando-se como uma população estável e com baixos níveis de senescência. As CTMs-TAF foram capazes de se diferenciar, in vitro em células adipogênicas, condrogênicas e osteogênicas na presença de factores de indução linhagem específica. Quando injetada em camundongos nude, as CTMs-TAF não foram capazes de dar origem a teratocarcinomas. Estes resultados demonstram que as CTMs-TAF possuem propriedades que sugerem a sua possível utilização na terapia celular.

Palavras-chave: Fontes. Diferenciação. Gato. Proliferação. Terapia celular. 


\section{Abstract \\ Biological of stem cells feline mesenchymal got from niches present in adipose tissue aiming its therapeutic application in veterinary medicine}

Adipose tissue has been a potential source for obtaining mesenchymal stem cells (MSCs). Recent studies have shown that MSCs have potential for use in basic and applied research. They can be obtained, in large quantities, by means of local anesthesia and with the minimum of discomfort; the MSCs have been object of intense research. In this study, feline adipose tissue, obtained through a biopsy performed in the subcutaneous region, was processed in order to obtain a morphologically homogeneous cell population. Feline adipose tissue-derived mesenchymal stem cells (MSCs-FAT) could be maintained in vitro in exponential growth until the $9^{\text {a }}$ passage presenting as a stable population with low levels of senescence. CTMs-FAT were able to differentiate in vitro in adipogenic, chondrogenic and osteogenic cells in the presence of specific lineage induction factors. When injected into nude mice the CTMs-FAT were not able to give rise to teratocarcinomas. These results demonstrate that CTMsFAT have properties that suggest their possible use in cell therapy.

Keywords: Cat. Cell Therapy. Differentiation. Prolliferation. Source.

\section{Introdução}

As células-tronco mesenquimais (CTMs) também denominadas células de reserva, encontramse localizadas em microambientes, denominados nichos. Nestes permanecem em estado quiescente sendo ativadas, ao longo da vida do indivíduo, em momentos de lesões, injurias ou de reposição celular devido ao processo natural de morte celular. As CTMs, por definição, são células indiferenciadas com alto potencial de proliferação, auto-renovação e diferenciação em diferentes tipos celulares como osteoblastos (DENNIS; CAPLAN, 1996), condrócitos (JOHNSTONE et al., 1998), adipócitos (DENNIS et al., 1999), e cardiomiócitos (TOMA et al., 2002).

Estando presentes em todos os tecidos que constituem o indivíduo, as CTMs são responsáveis pela manutenção da homeostase e reparação tecidual durante o transcorrer da vida do animal (KFOURY; SCADDEN, 2015; TSIMBOURI, 2015). Quando introduzidas no organismo, as CTMs adquirem tanto a morfologia como funcionalidade das células danificadas de forma a restaurar o tecido injuriado. Esta capacidade se deve ao grande número de moléculas bioativas que atuam modulando a resposta inflamatória, angiogênese e mitose das células envolvidas no processo de reparação tecidual (DIMARINO et al., 2013; MURPHY et. al., 2013; CAPLAN et al., 2015a; 2015b).

As CTMs vêm sendo obtidas a partir de diferentes espécies de vertebrados dentre os quais murinos (MEIRELLES; NARDI, 2003), ovinos (RENTSCH et al., 2010), suínos (RINGE et al., 2002), 
eqüinos (WORSTER et al., 2000) e humanos (JONES et. al., 2002). Em cães, as CTMs foram isoladas a partir de diferentes fontes como medula óssea (KADIYALA et al., 1997), tecido adiposo (NEUPANE et al., 2008), líquido amniótico (CHOI et al., 2013), músculo (KISIEL et al., 2012) e cordão umbilical (SEO et al., 2009). Já em felinos, as CTMs foram isoladas a partir da medula óssea (MARTIN et. al., 2002) e sangue periférico (SATO et. al., 2016). A importância de se estabelecer linhagens de CTMs a partir de diferentes fontes teciduais foi demonstrada por diferentes grupos de pesquisa uma vez que, a fonte tecidual pode estar diretamente relacionada ao sucesso da terapia celular (FILIOLI et al., 2011; REICH et al., 2012; KISIEL et al., 2012).

$\mathrm{Na}$ medicina veterinária, as CTMs têm demonstrado sua eficácia terapêutica em animais acometidos por lesões tendíneas (LEE et al., 2015; GEBUREK et al., 2017), osteoartrites (CUERVO et al., 2014; HARMAN et. al., 2016; KRISTON-PÁl et al., 2017), lesão medular (PENHA et al., 2014; KIM et. al., 2015; 2016), seqüela neurológica de cinomose (BRITO et. al., 2010), lesões na córnea (MORIYAMA et. al., 2014), aplasia medular (GATTI et. al., 2014; SANTOS et. al., 2017a), asma (TRZIL et al., 2015), lesões cutâneas (KIN et. al., 2013), Complexo Gengivite Estomatite Felina (ARZI et. al., 2016; 2017; ASSIS et. al., 2017) e úlceras (ALY et. al., 2014; ALAMOUDI et. al., 2014). Dentre as fontes de células-tronco mais utilizadas na medicina veterinária estão a medula óssea (FRIMBERGER et al., 2006), tecido adiposo (VIDAL et al., 2007) e cordão umbilical (KOCH et al., 2007). Dentre estas, as células provenientes do tecido adiposo destacam-se por sua facilidade de obtenção e abundância, proporcionando o mínimo desconforto para o animal (SANTOS, 2017b).

Neste estudo as CTMs isoladas a partir de nichos celulares presentes no tecido adiposo de felinos, foram avaliadas quanto ao seu potencial de proliferação, diferenciação, senescência e tumorigenicidade, visando sua utilização clínica na medicina veterinária.

\section{Materiais e Métodos}

O tecido adiposo foi obtido durante o processo de castração de animais doadores, tanto clinicamente como laboratorialmente saudáveis, com até seis meses de vida. O procedimento foi aprovado pelo Comitê de Ética no Uso de Animais número 4/2016. Foi retirado da porção abdominal interna mais precisamente da região de incisão pré-retro umbilical aproximadamente $2 \mathrm{~g}$ de tecido adiposo. Os proprietários dos animais forneceram os materiais mediante consentimento livre e esclarecido.

O tecido adiposo foi lavado em 1X PBS (phosphate buffered saline) de forma a retirar sangue e debris. Após a lavagem o tecido foi mantido durante 30 minutos a $37^{\circ} \mathrm{C} / 5 \%$ de $\mathrm{CO}_{2}$ em presença de $0,075 \%$ de colagenase tipo IV. Foi adicionado $5 \mathrm{~mL}$ de meio basal sendo o sobrenadante retirado e centrifugado durante 5 minutos a $200 \mathrm{~g}$. O precipitado foi ressuspenso e transferido para uma garrafa de cultivo de $25 \mathrm{~cm}^{2}$ a qual foi mantida a $37^{\circ} \mathrm{C} / 5 \% \mathrm{CO}_{2}$ durante 48 horas em presença de meio basal quando o mesmo foi trocado. Os repiques subseqüentes foram feitos por meio de ação enzimática utilizando $0.025 \%$ de tripsina (ZUK et al., 2001). 
A análise tumorgênica foi realizada em camundongos nudes. Foram utilizados três animais, mantidos em ambiente estéril durante o período de 90 dias os quais receberam a infusão de $2 \times 10^{6}$ CTMs-TAF, na 4a passagem, pela via intraperitoneal.

Para a análise proliferativa foi isolada uma colônia das CTMs-TAF e expandida até atingir uma confluência de $70 \%$ em uma garrafa de $25 \mathrm{~cm}^{2}$. As células foram removidas enzimaticamente (tripsina $0.025 \%$ ) e distribuídas, em triplicatas, em garrafas de $25 \mathrm{~cm}^{2}$ na concentração de $10^{5}$ células. Após três dias as células foram removidas, contadas em hemacitômetro e distribuídas em três novas garrafas de $25 \mathrm{~cm}^{2}$ na concentração de $1 \times 10^{5}$ células. O processo foi repetido até a 12a passagem (WINCK, 2009).

O estudo da senescência das CTMs-TAF foi realizado nos cultivos da $2^{2}$ passagem até a $8^{a}$ passagem por meio da atividade da $\beta$-galactosidase. As CTMs-TAF foram lavadas em PBS, fixadas por 5 min em presença de formaldeído $2 \%$, lavadas com PBS e incubadas em presença da solução de marcação de $\beta$-galactosidase constituida por $1 \mathrm{mg} / \mathrm{ml}$ de X-Gal, $40 \mathrm{mM}$ de ácido cítrico, PBS (pH 6.0), $5 \mathrm{mM}$ de $\mathrm{C}_{6} \mathrm{~N}_{6} \mathrm{FeK}_{3}, 150 \mathrm{mM}$ de $\mathrm{NaCl}$ e $2 \mathrm{mM} \mathrm{MgCl}_{2}$ sendo posteriormente analisadas ao microscópio óptico T100 (ZUK et al., 2001).

O potencial de diferenciação osteogênico das CTMs-TAF foi analisado na 4a passagem através do cultivo em meio basal Dulbecco's Modified Eagle's Medium-High Glucose, 15\% de soro fetal bovino, $1 \%$ de antibiótico (Penicilina $10.000 \mathrm{mg} / \mathrm{mL}$, Streptomicina $10.000 \mathrm{mg} / \mathrm{mL}$ ), 1\% de I-glutamina $(200 \mathrm{~mm})$ e $1 \%$ de aminoácidos não essenciais $(200 \mathrm{~mm})$ durante o período de 24 horas na concentração inicial de $1 \times 10^{5}$ células. Após $24 \mathrm{~h}$, o meio foi trocado para o de diferenciação osteogênica Dulbecco's Modified Eagle's Medium - Low Glucose (DMEM-LG), 1\% de 10-5 M de dexametasona, $1 \% 5 \mathrm{mM}$ de acido ascórbico, $10 \%$ de soro fetal bovino e 1\% Streptomicina/Penicilina (Penicilina Penicilina 10.000 $\mathrm{mg} / \mathrm{mL}$, Streptomicina $10.000 \mathrm{mg} / \mathrm{mL}$ ). A troca do meio foi feita a cada três ou quatro dias. No 100 dia foi adicionado $1 \%$ de $200 \mathrm{mM}$ de $\beta$-glicerolfosfato ao meio de cultura e também nas trocas subseqüentes. As células foram mantidas em cultura até o 21ㅇdia de diferenciação. A caracterização das células foi feita por meio da coloração de Von Kossa (ZUK et al., 2001).

Para a análise do potencial de diferenciação adipogênico as CTMs-TAF, na 4a passagem, foram cultivadas em meio basal durante o período de $24 \mathrm{~h}$ na concentração inicial de $1 \times 10^{5}$ células. Após as 24 horas o meio foi trocado para o de diferenciação adipogênica composto por Dulbecco's Modified Eagle's Medium - HIGH Glucose, 10\% de soro fetal bovino, $1 \mathrm{mM}$ de dexametasona, $100 \mathrm{mM}$ de indometacina, 0,5M de isobutilmetilxantina, $10 \mu \mathrm{M}$ de insulina e 1\% de antibiótico (Penicilina 10.000 $\mathrm{mg} / \mathrm{mL}$, Streptomicina $10.000 \mathrm{mg} / \mathrm{mL}$ ), a troca do meio foi feita a cada três ou quatro dias. As células foram mantidas em cultura até o 21 ㅇ dia de diferenciação. As células foram então fixadas por 60 minutos a temperatura ambiente em presença de paraformaldeido $4 \%$, lavadas 3 vezes com etanol $70 \%$, mantidas a temperatura ambiente por cinco minutos com Oil Red $O$ sendo posteriormente lavadas 3 vezes com água destilada (ZUK et al., 2001).

Para a análise do potencial de diferenciação condrogênico as CTMs-TAF, na 4a passagem, foram transferidas, na concentração $1 \times 10^{6}$, para tubos falcon de $15 \mathrm{~mL}$, centrifugadas a $200 \mathrm{~g}$ por 5 minutos. Em seguida foram cultivadas na presença de meio Dulbecco's Modified Eagle's Medium - HIGH Glucose suplementado com 1\% de soro fetal bovino, 6,25 mM de insulina, 0,1 mM de dexametasona, $1 \mathrm{mM}$ de piruvato de sódio, $10 \mathrm{ng} / \mathrm{mL}$ TGF- $\beta 1$ e $1 \%$ de antibiótico (Penicilina $10.000 \mathrm{mg} / \mathrm{mL}$, Rev. Elet. Cient. UERGS, v.4, n.3, p. 368-379, 2018. 
Streptomicina $10.000 \mathrm{mg} / \mathrm{mL}$ ) sendo que a troca do meio indutor foi realizada diariamente durante 21 dias. Posteriormente o pellet esférico formado foi fixado, incluso, cortado e corado com azul de toluidina (JOHNSTONE et al., 1998).

\section{Resultados e Discussão}

Neste estudo demonstrou-se que pequenos fragmentos de tecido adiposo de felinos, $2 \mathrm{~g}$, foram capazes de ser uma fonte continua e efetiva de CTMs durante longos períodos, quando mantidos em cultura. O processo de obtenção das CTMs-TAF mostrou-se seguro e minimamente invasivo uma vez que o tecido adiposo pode ser obtido no momento da castração ou através de uma pequena incisão. As fontes CTMs obtidas de forma menos invasivas vêm se mostrando mais atrativas para sua utilização na terapia com células-tronco (SANTOS, 2017).

Os resultados obtidos demonstram que as CTMs-TAF apresentavam a capacidade de se aderir ao plástico, tendo começado a apresentar morfologia fibroblastoide após o 10! dia em cultivo (Figura 1A). Foi observado uma rápida expansão celular, já na primeira passagem, quando em um período de 72 horas, $80 \%$ da área cultivável foi preenchida. As CTMs-TAF demonstraram possuir uma rápida capacidade de formar unidades de colônia (CFU - colony forming unit).

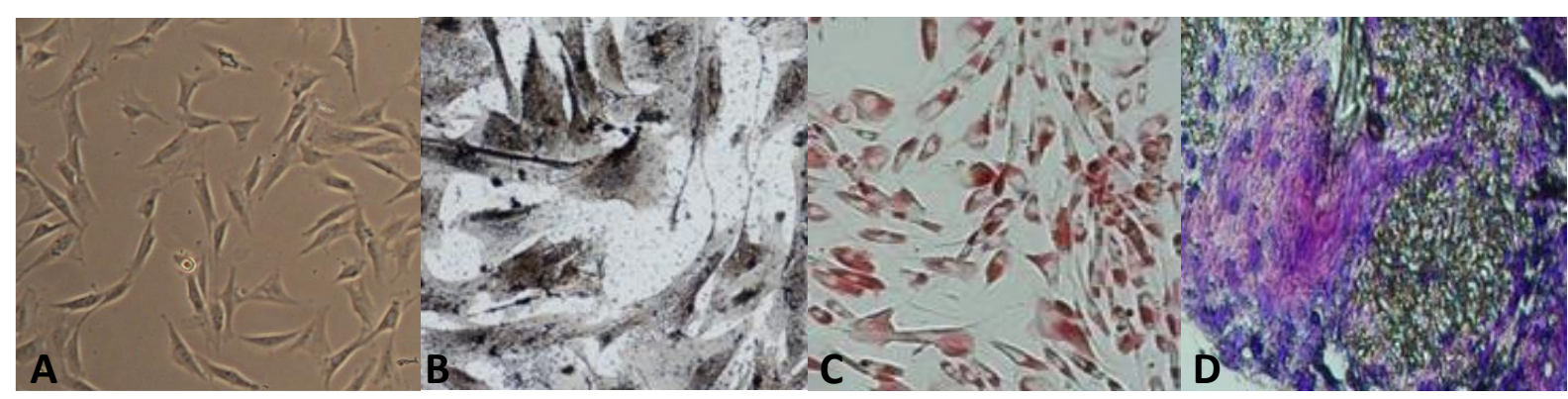

Figura 1 - (A) Morfologia fibroblastóide das CTMs-TAF, obj. 10x; (B) Diferenciação osteogênica das CTMs-TAF. Marcação com Von Kossa demonstrando a calcificação da matriz extracelular, obj. 40x; (C) Diferenciação adipogênica das CTMs-TAF. A marcação com Oil Red O demonstra o acúmulo de gotas lipídicas na cultura, obj. 20x; (D) Diferenciação condrogênica das CTMs-TAF. Marcação positiva para condrócitos por meio do azul de toluidina observada na metacromasia do pellet, obj. 40x.

A análise do potencial de diferenciação osteogênico, adipogênico e condrogênico foi feita com base em protocolos já estabelecidos (JOHNSTONE et al. 1998; ZUK et al. 2001) utilizando CTMs-TAF na $4^{a}$ passagem. A diferenciação osteogênica ocorreu de forma efetiva após o 210 dia sendo evidenciada por meio do processo de mineralização revelada pela formação de matriz extracelular calcificada identificada por meio da marcação com Von Kossa (Figura 1B). O potencial de diferenciação adipogênico das CTMs-TAF foi demonstrado após 21 dias, por meio da marcação com Oil Red $O$, a qual revela o acúmulo citoplasmático de gotas lipídicas ao redor do núcleo das células diferenciadas (Figura 1C). Já a diferenciação condrogênica foi realizada durante o período de 21 dias, sendo obtida 
uma micromassa celular a partir do 10 dia de suspensão das CTMs-TAF. Os cortes histológicos marcados com azul de toluidina demonstraram áreas cartilaginosas (Figura 1D).

Quando injetadas em camundongos nude, as CTMs-TAF, na 4a passagem, não foram capazes de induzir a formação de teratocarcinomas, resultado extremamente relevante uma vez que se objetiva a utilização terapêutica das CTMs-TAF no tratamento de diversas doenças que acometem os felinos. A análise do potencial proliferativo foi avaliado com base no crescimento exponencial das células isoladas a partir das CFU. A contagem celular ocorreu a cada três dias, tendo como origem a concentração de $10^{5}$ células. Observou-se um crescimento exponencial até a $9^{a}$ passagem após a qual foi observada uma queda acentuada tendo sido detectada uma diferenciação adipogênica espontânea das CTMs-TAF (Gráfico 1).

A partir da $10^{\underline{a}}$ passagem ocorre um aumento na taxa de senescência celular quando comparada a taxa de proliferação celular. Embora o crescimento exponencial das CTMs-TAF ocorra até a 9a passagem, terapeuticamente as CTMs tendem a ser utilizadas em baixas passagens de forma a minimizar a possibilidade de instabilidade cromossômica no cultivo celular (BINATO et. al., 2013).

A análise da senescência das CTM-TAF realizada nos cultivos de CTMs-TAF da 2a passagem até a 12a passagem, por meio do protocolo da $\beta$-galactosidase, demonstrou a ausência de marcação da $2 \underline{a}$ passagem até a 9a passagem. A partir da 10aㅡ passagem, a taxa de senescência começou a se elevar consideravelmente.

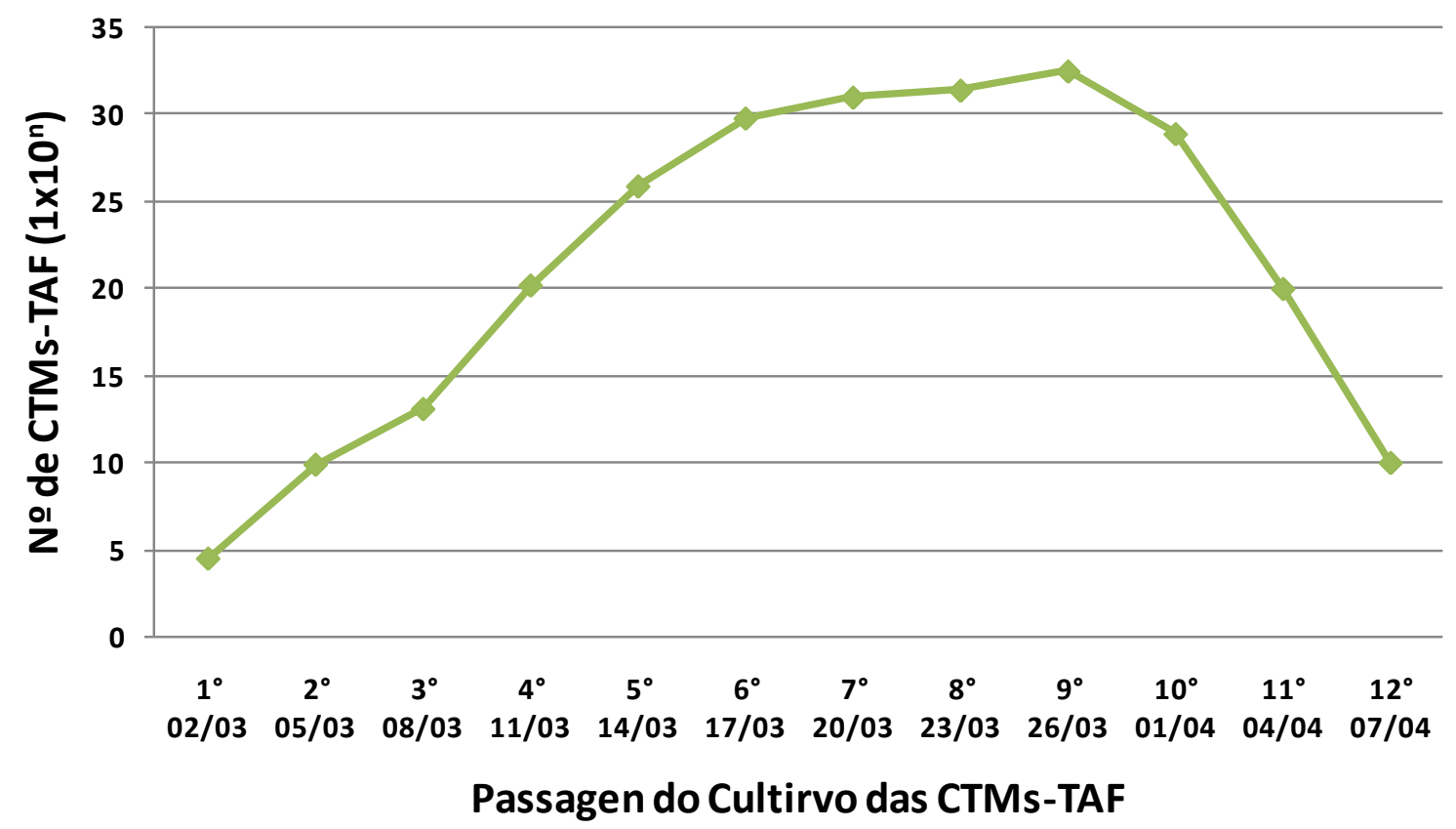

Gráfico 1 - Curva de crescimento das CTMs-TAF. Neste gráfico, colônias de células-tronco foram expandidas até atingirem a concentração $10^{5}$ células. As populações foram avaliadas quanto ao seu crescimento celular a cada três dias durante 12 passagens demonstrando um considerável crescimento exponencial até a 9a passagem após a qual se observou uma queda dos valores.

A eficiência constatada nos processos de formação de colônia, proliferação e diferenciação em três linhagens mesodermais das CTMs-TAF assim como a análise tumorgênica e senescência, abrem 
uma nova perspectiva para a utilização terapêutica das CTMs-TAF em animais doentes ou lesionados. No contexto terapêutico, o fator vias de administração têm se mostrado extremamente relevante. Para tal, deve-se levar em consideração as seguintes características: ser de fácil realização; ser o menos invasiva e traumática; causar mínimos efeitos colaterais e com a maior taxa de sobrevivência celular, fatores estes extremamente relevantes para o sucesso da terapia celular.

As vias de administração mais utilizadas são a endovenosa, de fácil acesso e pouco invasiva e a via intraperitoneal que permite a administração de um número elevado de células com menor risco de formação de êmbolos (XU et. al., 2008; WEl et. a., 2010). Também apresenta menos efeitos colaterais quando comparada à administração endovenosa uma vez que administradas em altas concentrações, estudos sugerem a possível formação de tromboembolismo pulmonar (MOLL et. al., 2012).

Desta forma, a utilização terapêutica das CTMs na medicina veterinária pode representar uma nova perspectiva visando a melhoria da qualidade de vida dos animais acometidos por diferentes doenças.

\section{Conclusão}

Os resultados são pioneiros em demonstrar que as células-tronco mesenquimais isoladas do tecido adiposo de felinos apresentam morfologia fibroblastóide, um alto potencial de diferenciação em tecidos de origem mesodérmica, proliferação celular e baixa taxa de senescência nas passagens iniciais assim como a não capacidade de originar teratocarcinomas. Estes dados indicam que as células-tronco mesenquimais provenientes de nichos presentes no tecido adiposo de felinos, são excelentes candidatas a serem utilizadas no tratamento de diversas doenças que acometem os felinos.

\section{Referências}

ALOUDI, N.M.; EL ASHIRY, E.A.; FARSI, N.M. Treatment of oral ulcers in dogs using adipose tissuederived mesenchymal stem cells. The Journal of Clinical Pediatric Dentistry, Birmingham, Alabama, v.38, n.3, p.215-22, 2014.

ALY, L. A.; EL-MENOUFY, H.; SADEQ, H.S. Efficiency of systemic versus intralesional bone marrowderived stem cells in regeneration of oral mucosa after induction of formocresol induced ulcers in dogs. Dentistry Research Journal, Isfahan, v.11, n.2, p.212-21, 2014. 
ARZI, B. et al. Therapeutic Efficacy of Fresh, Autologous Mesenchymal Stem Cells for Severe Refractory Gingivostomatitis in Cats. Stem Cells Translational Medicine, Durham, Carolina do Norte, v.5, n.1, p.75-86. 2016

ARZI, B. et al. Therapeutic Efficacy of Fresh, Allogeneic Mesenchymal Stem Cells for Severe Refractory Feline Chronic Gingivostomatitis. Stem Cells Translational Medicine, Durham, Carolina do Norte, v.6, n.8, p.1710-1722, 2017.

ASSIS, T.L.S.; WINCK, C.P.; SANTOS, E.J.C. Análise da Viabilidade Terapêutica das Células-Tronco Mesenquimais Alogênicas no Tratamento de Felino Acometido por Complexo Gengivite Estomatite Felina. Revista Científica Multidisciplinar Núcleo do Conhecimento, São Paulo, Ano 02, v. 1, p.470482, 2017.

BINATO, R.; SOUZA , F.T.; LAZZAROTTO-SILVA, C. Stability of human mesenchymal stem cells during in vitro culture: considerations for cell therapy. Cell Proliferation, Oxford, v.46, n.1, p.10-22, 2013.

BRITO, H. F. V. et al. Tratamento de sequelas neurológicas em cães, causadas por infecção pelo vírus da cinomose, através do transplante alogênico de células mononucleares de medula óssea. Revista Científica de Medicina Veterinária. Pequenos Animais e Animais de Estimação, Curitiba, v.24, n.8, p.26-29, 2010.

CAPLAN, A.I.; SORRELL, J.M. The MSC curtain that stops the immune system. Immunology Letter, Amsterdam, v.168, n.2, p.136-9, 2015a.

CAPLAN A.I.; HARIRI R. Body Management: Mesenchymal Stem Cells Control the Internal Regenerator. Stem Cells Translational Medicine, Durham, Carolina do Norte, v.4, n.7, p.695-701, 2015b.

$\mathrm{CHOI}, \mathrm{S}$. A. et al. Isolation of canine mesenchymal stem cells from amniotic fluid and differentiation into hepatocyte-like cells. In Vitro Cell Developmental Biology Animal, Columbia, Maryland, Jan, v. 49, n. 1, p. $42-51,2013$.

CUERVO, B. et al. Hip osteoarthritis in dogs: a randomized study using mesenchymal stem cells from adipose tissue and plasma rich in growth factors. International journal of molecular sciences, Basel, v.15, n.8, p.13437-60, 2014.

DENNIS, J.E.; CAPLAN, A.I. Differentiation potential of conditionally immortalized mesenchymal progenitor cells from adult marrow of a $\mathrm{H}-2 \mathrm{~Kb}$-tsA58 transgenic mouse. Journal Cell Physiology, Filadelfia, v.167, n.3, p.523-538, 1996. 
DENNIS, J.E.; MERRIAM, A.; AWADALLAH, A. A quadric potential mesenchymal progenitor cell isolated from the marrow of an adult mouse. Journal Bone Miner Research, Nova York, v.14, n.5, p.700-709, 1999.

DIMARINO, A.M.; CAPLAN, A.I.; BONFIELD, T.L. Mesenchymal stem cells in tissue repair. Frontiers Immunology, Lusiana, v.4, p.201, 2013.

FILIOLI, U.M.; VALENTINI, L.; LANGE-CONSIGLIO, A. et. al. Isolation, proliferation, cytogenetic, and molecular characterization and in vitro differentiation potency of canine stem cells from foetal adnexa: a comparative study of amniotic fluid, amnion, and umbilical cord matrix. Molecular Reproduction Development, Nova York, v.78, n.5, p.361-373, 2011.

FRIMBERGER, A. E.; MOORE, A. S.; RASSNICK, K. M. A combination chemotherapy protocol with dose intensification and autologous bone marrow transplant (VELCAP-HDC) for canine lymphoma. Journal Veterinary International Medicine, Filadelfia, v.20, n,2, p.355-64, 2006.

GATTI A; MARTINS, D.S.; SANTOS, E.J.C. Cell therapy in the treatment of myeloid aplasia - a case report. Revista Científica de Medicina Veterinária - Pequenos Animais e Animais de Estimação, São Paulo, v.12, n.41, p.296-303, 2014.

GEBUREK, F. et al. Effect of single intralesional treatment of surgically induced equine superficial digital flexor tendoncore lesions with adipose-derived mesenchymal stromal cells: a controlled experimental trial. Stem Cell Research Therapy, Londres, v.8, n.1, p.129, 2017.

HARMAN, R. et al. A Prospective, Randomized, Masked, and Placebo-Controlled Efficacy Study of Intraarticular Allogeneic Adipose Stem Cells for the Treatment of Osteoarthritis in Dogs. Frontiers Veterinary in Science, Lusiana, v.3, 2016.

JOHNSTONE, B.; HERING, T.M.; CAPLAN, A.I. In vitro chondrogenesis of bone marrow-derived mesenchymal progenitor cells. Experimental Cell Research, Nova York, v.238, n.1, p.265-272, 1998.

JONES, E.A.; KINSEY, S.E.; ENGLISH, A. Isolation and characterization of bone marrow multipotential mesenchymal progenitor cells. Arthritis Rheumatology Journal, Atlanta, v.46, n.12, p,3349-3360, 2002.

KFOURY, Y.; SCADDEN, D.T. Mesenchymal cell contributions to the stem cell niche. Cell Stem Cell, Cambridge, v.16, n.3, p.239-253, 2015. 
KADIYALA, S.; YOUNG, R.G.; THIEDE, M.A. Culture expanded canine mesenchymal stem cells possess osteochondrogenic potential in vivo and in vitro. Cell Transplantation, Elmsford, Nova York, v.6, n.2, p.125-134, 1997.

KIM, J.W.; LEE, J.H.; LYOO, Y.S. The effects of topical mesenchymal stem cell transplantation in canine experimental cutaneous wounds. Veterinary Dermatology, Oxford, v.24, n.2, p.242-253, 2013.

$\mathrm{KIM}$, Y. et al. Antioxidant and anti-inflammatory effects of intravenously injected adipose derived mesenchymal stem cells in dogs with acute spinal cord injury. Stem Cell Research Therapy, Londres, v.26, n.6, p.229, 2015.

KIM, Y. et al. Transplantation of adipose derived mesenchymal stem cells for acute thoracolumbar disc disease with no deep pain perception in dogs. Journal of Veterinary Science, Seul, v.17, n.1, p.123126, 2016.

KISIEL, A.H.; MCDUFFEE, L.A.; MASAOUD, E. Isolation, characterization, and in vitro proliferation of canine mesenchymal stem cells derived from bone marrow, adipose tissue, muscle, and periosteum. American Journal of Veterinary Research, Chicago, v.73, n.8, p.1305-1317, 2012.

$\mathrm{KOCH}$, T.G.; HEERKENS, T.; THOMSEN, P.D. Isolation of mesenchymal stem cells from equine umbilical cord blood. BMC Biotechnology, Londres, v.7, p.26, 2007.

KRISTON-PÁL, É. et al. Characterization and therapeutic application of canine adipose mesenchymal stem cells to treat elbow osteoarthritis. Canadian Journal of Veterinary Research, Ottawa, v.81, n.1, p.73-78, 2017.

LEE, S.Y. et al. Treatment of Lateral Epicondylosis by Using Allogeneic Adipose-Derived Mesenchymal Stem Cells: A Pilot Study. Stem Cells, Durham, Carolina do Norte, v.33, n.10, p.2995-3005, 2015.

MARTIN, D. R.; COX, N.R.; HATHCOCK, T.L. Isolation and characterization of multipotential mesenchymal stem cells from feline bone marrow. Experimental Hematology ${ }_{2}$ Copenhague, v.30, n.8, p.879-886, 2002.

MEIRELLES, L.D.A.S.; NARDI, N.B. Murine marrow-derived mesenchymal stem cell: isolation, in vitro expansion, and characterization. British Journal of Haematology, Oxford, v.123, n.4, p.702-711, 2003.

MOLL, G.; RASMUSSON-DUPREZ, I.; VON BAHR, L. Are therapeutic human mesenchymal stromal cells compatible with human blood? Stem Cells, Durham, Carolina do Norte, v.30, n.7, p.1565-1574, 2012. 
MORIYAMA, H.; KASASHIMA, Y.; KUWANO, A. Anatomical location and culture of equine corneal epithelial stem cells. Veterinary Ophthalmology, Osney Mead, Oxford, v.17, p.106-112, 2014.

MURPHY, M.B.; MONCIVAIS, K.; CAPLAN, A.I. Mesenchymal stem cells: environmentally responsive therapeutics for regenerative medicine. Experimental Molecular Medicine, Seul, Nov 15, p.45-54, 2013.

NEUPANE, M.; CHANG, C.C.; KIUPEL, M.Y. Isolation and characterization of canine adipose-derived mesenchymal stem cells. Tissue Engineering Part A, New Rochelle, Nova York , v.14, n.6, p.10071015,2008

PENHA, E. M.; MEIRA, C.S.; GUIMARÃES, E.T. Use of autologous mesenchymal stem cells derived from bone marrow for the treatment of naturally injured spinal cord in dogs. Stem Cells International, Londres, 2014.

REICH, C.M.; RAABE, O.; WENISCH, S. Isolation, culture and chondrogenic differentiation of canine adipose tissue- and bone marrow-derived mesenchymal stem cells--a comparative study. Veterinary research communications, Amsterdam, v.36, n.2, p.139-148, 2012.

RENTSCH, C.; HESS, R.; RENTSCH, B. Ovine bone marrow mesenchymal stem cells: isolation and characterization of the cells and their osteogenic differentiation potential on embroidered and surfacemodified polycaprolactone-co-lactide scaffolds. In Vitro Cell Development Biology Animal, Columbia, Maryland, v.46, n.7, p.624-634, 2010.

RINGE, J.; KAPS, C.; SCHMITT, B. Porcine mesenchymal stem cells. Induction of distinct mesenchymal cell lineages. Cell Tissue Research, Berlim, v.307, n.3, p.321-327, 2002.

SANTOS, E.J.C.; WINCK, C.P.; BRAGA, C.L. Estudo Eficácia E Segurança Terapêutica Das CélulasTronco Mesenquimais Alogênicas No Tratamento de Felinos Acometidos pela Doença Renal Crônica e Resistentes a Eritropoetina Sintética. Revista Científica Multidisciplinar Núcleo do Conhecimento, São Paulo, Ano 02, v.1. p. 296-309, 2017a.

SANTOS, E.J.C. Análise da Aplicação Terapêutica das Células Tronco na Medicina Veterinária. Revista Científica Multidisciplinar Núcleo do Conhecimento, São Paulo, Ano 02, v. 1, p. 269-295, 2017b.

SATO, K. Isolation and characterisation of peripheral blood-derived feline mesenchymal stem cells. Veterinary Journal, Londres, v.216, p.183-8, 2016. 
SEO, M.S.; JEONG, Y.H.; PARK, J.R. Isolation and characterization of canine umbilical cord bloodderived mesenchymal. Stem cells, Seul, v.10, n.3, p.181-187, 2009.

TOMA, C.; PITTENGER, M.F.; CAHILL, K.S. Human mesenchymal stem cells differe- ntiate to a cardiomyocyte phenotype in the adult murine heart. Circulation, Dallas, v.105, p.93-98, 2002.

TRZIL, J.E.; MASSEAU, I.; WEBB, T.L. Intravenous adipose-derived mesenchymal stem cell therapy for the treatment of feline asthma: a pilot study. Journal of Feline Medicine and Surgery, Londres, Sep 17, 2015.

TSIMBOURI, P. M. Adult Stem Cell Responses to Nanostimuli. Journal of Functional Biomaterials, Basel, v.6, n.3, p.598-622, 2015.

VIDAL, M.A. et al. Characterization of equine adipose tissue-derived stromal cells: adipogenic and osteogenic capacity and comparison with bone marrow-derived mesenchymal stromal cells. Veterinary Surgery, Filadelfia, v.36, n.7, p.613-22, 2007.

WEI, H.; OOI, T.H.; TAN, G. Cell delivery and tracking in post-myocardial infarction cardiac stem cell therapy: an introduction for clinical researchers. Heart Fail Review, Norwell, v.15, n.1, p.11-14, 2010.

WINCK, C.P. Cultivo e caracterização de células-tronco de membrana amniótica canina. 2009. Trabalho de Conclusão de Curso - Graduação em Ciências Biologias, Universidade de Santo Amaro, São Paulo, 2009.

WORSTER, A. A.; NIXON, A. J.; BROWER-TOLAND, B. D. Williams J. Effect of transforming growth factor beta1 on chondrogenic differentiation of cultured equine mesenchymal stem cells. American Journal of Veterinary Research, Chicago, v.61, n.9, p.1003-1010, 2000.

XU, Y. Q.; LIU, Z. C. Therapeutic potential of adult bone marrow stem cells in liver disease and delivery approaches. Stem Cell Revew, Totowa, v.4, n.2, p.101-112, 2008.

ZUK, P. A. et al. Multilineage cells from human adipose tissue: implications for cell-based therapies. Tissue Engineering, Nova York, v.7, n.2, p.211-228, 2001. 